\title{
Morbidity Management and Disability Prevention of Lymphatic Filariasis
}

\section{OPEN ACCESS}

Manuscript ID:

ECO-2021-09033783

Volume: 9

Issue: 3

Month: June

Year: 2021

P-ISSN: 2319-961X

E-ISSN: 2582-0192

Received: 24.02 .2021

Accepted: 15.04.2021

Published: 01.06.2021

Citation:

Sangamithra, A., and P. Dhavamani. "Morbidity Management and Disability Prevention of Lymphatic Filariasis." Shanlax International Journal of Economics, vol. 9, no. 3, 2021, pp. 24-28.

DOI:

https://doi.org/10.34293/ economics.v9i3.3783

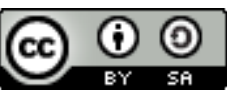

This work is licensed under a Creative Commons Attribution-ShareAlike 4.0 International License

\section{A. Sangamithra}

Professor, Department of Economics, Bharathiar University, Coimbatore, Tamil Nadu, India

(D) https://orcid.org/0000-0003-4761-8150

\section{P. Dhavamani}

Research Scholar, Department of Economics

Bharathiar University, Coimbatore, Tamil Nadu, India

\section{Abstract}

Lymphatic Filariasis (LF) vector-borne, chronically disabling parasitic contamination inflicting elephantiasis, lymphoedema, and hydrocele, is a leading public strength convenience as nicely as serious socioeconomic trouble due to its morbid condition, social stigma, and massive financial loss in many creating nations, and this sickness has been ranked as the second primary purpose of long-term continual incapacity worldwide. World Health Assembly decision in 1997 for Eliminate of Lymphatic Filariasis (ELF) via 2020 made all the filaria endemic nations in the world put efforts for its removing with the aid of regularly decreasing and finally interrupting the transmission of Lymphatic Filariasis (LF). Another lookup is wished to aid efforts to 'scale-up morbidity manipulation and incapacity alleviation programs at the countrywide stage and to report the extent to which anti-filarial drug cure influences the direction of filariasis associated disorder.

Keywords: Lymphatic Filariasis (LF), Morbidity, Lymphoedema, MMDP, GPELF

\section{Introduction}

Lymphatic Filariasis (LF) is a continual infectious ailment that unfolds worldwide. Lymphatic filariasis (LF), a vector-borne, chronically disabling parasitic contamination inflicting elephantiasis, lymphoedema, and hydrocele is a leading public strength convenience nicely as serious socioeconomic trouble due to its morbid condition, social stigma, and massive financial loss in many creating nations. This sickness has been ranked as the second primary purpose of long-term continual incapacity worldwide. The inability brought about renders these bothered unproductive and unable to contribute to countrywide and their man or woman monetary development. Lymphatic Filariasis (LF) is a disease of low mortality. However, it is international public health trouble because it is a reason for extreme disabilities and socioeconomic problems. The different pillars of the LF management program are once carried out to evaluate it and impart hints to optimize the use of accessible resources. Consequently, there is a persistent need for capitalizing on the Morbidity Administration Programs, and this paper aims to estimate the Health fitness and monetary burdens of Lymphatic Filariasis (Chandrasena, 2018).

\section{Agent and transmission of LF}

LF is precipitated using three nematodes, Wuchereria bancrofti, Brugiamalayi, and Brugiatimori. These three parasites infect the human lymphatic device and are transmitted through Culex, Anopheles, and Mansonia mosquito vectors. About $95 \%$ of the disorder is brought on via W. bancrofti, in the SEA Region, and the relaxation by way of Brugiamalayi and Brugiatimori. Female mosquitoes suck the microfilariae at some stage in their blood meal. 
These microfilariae increase inside the mosquito physique via four steps and trade into infective larvae within 2-3 weeks. These enter a healthful man or woman throughout the subsequent blood meal and the character receives infected. These larvae turn out to be person male and woman inside a length of 8-12 months and begin producing microfilaria and proceed the cycle. The grownup worms stay for 5-8 years for growth, viability, and fertility of the parasites. Their liberation into the blood due to the death of parasites motives inflammatory reactions.

\section{Elimination of Lymphatic Filariasis}

World Health Assembly decision in 1997 for Eliminate of Lymphatic Filariasis (ELF) via 2020 made all the filaria endemic nations in the world put efforts for its removing with the aid of regularly decreasing and finally interrupting the transmission of Lymphatic Filariasis (LF). The strategic layout 2010-2020 has been formulated focusing on interrupting transmission using 2020 and supplying primary care to all humans struggling from LFrelated morbidity. It also addresses the Mass Drug Administration (MDA) on coverage, scaling up, surveillance, and challenges in initiating morbiditymanagement in all endemic countries. Its center of attention is to decorate and scale up associated offerings to attain full geographical insurance and get admission to lymphoedema administration and hydrocele surgeries. At the same time, nations but to initiate MDA to remove LF will undertake increased mapping and insurance evaluation protocols to speed up the efforts for reaching world removal using 2020 .

\section{Strategies for Managing Morbidity and Preventing Disability}

The Global Programme to Eliminate Lymphatic Filariasis (GPELF) grants morbidity care for those who go through disabling scientific manifestations. The contamination is mentioned to manifest frequently in childhood, while the disabilities commonly occur after 10-15 years due to the obstruction to the lymph waft and ensuing lymphoedema and hydrocele. LF is the most frequent motive of lymphoedema and hydrocele. The method on morbidity administration and incapacity prevention chiefly focuses on the care of acute infections, lymphoedema consisting of elephantiasis and hydrocele. Activities for managing different medical types of filarial ailment include chyluria, lymphocele, scrotal lymphoedema, tropical pulmonary Eosinophilia, lymphadenopathy, and haematuria, are covered under joint medical administration for the reason that public-health strategies to these problems have now not yet been established. Lymphatic filariasis is the principal overlooked tropical illness with disabling prerequisites connected with continual manifestations affecting health, social and monetary status, and the diseases share attributes that are economical and frequent for disability prevention (Kumari, 2020).

Table 1: Integrating Disability Management

\begin{tabular}{|c|c|c|}
\hline Components & $\begin{array}{l}\text { Lymphatic } \\
\text { Filariasis }\end{array}$ & $\begin{array}{l}\text { Commonalities } \\
\text { for Intervention }\end{array}$ \\
\hline Mobility & $\begin{array}{l}\text { Activity } \\
\text { limitation }\end{array}$ & $\begin{array}{l}\text { Prevention of } \\
\text { activity limitation }\end{array}$ \\
\hline $\begin{array}{l}\text { Commonly } \\
\text { affected Parts }\end{array}$ & $\begin{array}{l}\text { Foot hands and } \\
\text { Genitalia }\end{array}$ & $\begin{array}{l}\text { Care of hand, } \\
\text { foot, and other } \\
\text { organs }\end{array}$ \\
\hline Impairment & $\begin{array}{l}\text { Lymphatic } \\
\text { Function }\end{array}$ & $\begin{array}{l}\text { Need long-time } \\
\text { care }\end{array}$ \\
\hline WHO grading & Three grades & Appropriate care \\
\hline $\begin{array}{l}\text { Preventive } \\
\text { measures }\end{array}$ & $\begin{array}{l}\text { Early detection } \\
\text { and care of } \\
\text { entry lesions } \\
\text { and check acute } \\
\text { attacks }\end{array}$ & $\begin{array}{l}\text { Early home-based } \\
\text { care to prevent } \\
\text { worsening and } \\
\text { referral }\end{array}$ \\
\hline $\begin{array}{l}\text { Medical } \\
\text { emergencies }\end{array}$ & $\begin{array}{l}\text { Acute attacks, } \\
\text { ulcers, and } \\
\text { infections }\end{array}$ & $\begin{array}{l}\text { Fever, swelling, } \\
\text { pain, and loss of } \\
\text { function }\end{array}$ \\
\hline $\begin{array}{l}\text { The protective } \\
\text { device for feet }\end{array}$ & $\begin{array}{l}\text { Customized } \\
\text { protective } \\
\text { footwear }\end{array}$ & $\begin{array}{l}\text { Adequate } \\
\text { footwear } \\
\text { provision }\end{array}$ \\
\hline $\begin{array}{l}\text { Need for } \\
\text { Economic } \\
\text { Uplift }\end{array}$ & $\begin{array}{l}\text { Associated with } \\
\text { poverty, long } \\
\text { DALYs, and } \\
\text { wage loss }\end{array}$ & $\begin{array}{l}\text { Revolving loan, } \\
\text { SSCs formation, } \\
\text { and linkages with } \\
\text { welfare schemes }\end{array}$ \\
\hline Social Impact & $\begin{array}{l}\text { Stigma, } \\
\text { prejudices, } \\
\text { discrimination, } \\
\text { deprived human } \\
\text { rights }\end{array}$ & $\begin{array}{l}\text { Advocacy } \\
\text { and social } \\
\text { mobilization }\end{array}$ \\
\hline
\end{tabular}

Source: World Health Organization (WHO) 
Role and Partner of Morbidity Management and Disability Prevention

The partnership is a cornerstone of public health programs. The LF program works in close collaboration with a vast array of national, worldwide agencies. To be successful, the morbidity administration program requires the full involvement and coordination of all the following partners.

\section{Table 2: Role and Partner of Morbidity Management and Disability Prevention}

\begin{tabular}{|c|c|}
\hline Partner & Role \\
\hline $\begin{array}{l}\text { Global Programme } \\
\text { to Eliminate } \\
\text { Lymphatic } \\
\text { Filariasis (GPELF) }\end{array}$ & $\begin{array}{l}\text { Recommend with countrywide governments and boards for implementation of the program } \\
\text { - } \quad \text { mobilize sources and political commitment; } \\
\text { - supply technical guide in ability constructing and formulating policies and frameworks. }\end{array}$ \\
\hline WHO & $\begin{array}{l}\text { Coordinate with countrywide government/national project force/interagency coordinating } \\
\text { corporations in planning, monitoring, evaluation, and for implementation of countrywide } \\
\text { plans and frameworks; } \\
\text { grant technical aid in formulating policies, education to the governments in the } \\
\text { implementation of morbidity administration and prevention of incapacity programs; } \\
\text { - make a certain rights-based method in implementation; } \\
\text { - recommend for integration with different sickness programs/NTDs for implementation } \\
\text { of morbidity management; } \\
\text { - Inspire NGOs/academic establishments for implementation of cost-effective } \\
\text { interventions for scale-up. }\end{array}$ \\
\hline $\begin{array}{l}\text { National } \\
\text { Governments }\end{array}$ & $\begin{array}{l}\text { - enhance and put into effect countrywide plans in LF with a focal point on morbidity } \\
\text { management and prevention of disabilities; } \\
\text { - periodic evaluation of the implementation of LF programs in endemic areas with a focal } \\
\text { point on implementation of morbidity administration and prevention of disabilities; } \\
\text { - make sure appropriate fund float by the countrywide objectives and framework; } \\
\text { - interact public personal partnerships for scale-up of activities; } \\
\text { - contain different authorities corporations in the implementation of things to do and in } \\
\text { leveraging support; } \\
\text { - preserve political dedication and recommend with different stakeholders. }\end{array}$ \\
\hline $\begin{array}{l}\text { Persons affected } \\
\text { by Lymphatic } \\
\text { Filariasis }\end{array}$ & $\begin{array}{l}\text { Get entry to records about offerings available; } \\
\text { - contain and promote in Identifying the limitations and act on ignorance, stereotypes, and } \\
\text { discrimination that exist at several levels; } \\
\text { work with authorities and NGOs in planning, designing, and implementing the leprosy } \\
\text { programs and affect the decision-makers; } \\
\text { motivate the household participants and their communities for early identification, } \\
\text { therapy adherence, and incapacity care; } \\
\text { - the sensitizing neighborhood on lymphatic filariasis; } \\
\text { - } \quad \text { counseling sufferers on MDA and incapacity care; } \\
\text { - } \text { gather evidence and record to the involved authorities for troubles to be addressed; } \\
\text { practices amongst carrier carriers and in the community; } \\
\text { - sensitize the people affected via LF about collectivism and encourage them to be phase } \\
\text { of/enroll in self-support groups/networks; } \\
\text { - Inform, enchantment, and recommend for the safety of human rights and advocate for } \\
\text { high-quality services. }\end{array}$ \\
\hline $\begin{array}{l}\text { Academic and } \\
\text { research institutes }\end{array}$ & $\begin{array}{l}\text { - Researching on have an impact and results of services; on using integrated approaches; } \\
\text { - grant evidence and statistics for decision-makers. }\end{array}$ \\
\hline
\end{tabular}




\begin{tabular}{|l|l|}
\hline \multirow{2}{*}{ NGOs } & $\begin{array}{l}\text { Assist the countrywide governments in enhancing coverage, get right of entry to services for } \\
\text { individuals affected with the aid of lymphatic filariasis; }\end{array}$ \\
- $\quad$ recommend for the rights of folks affected using lymphatic filariasis \\
- Inclusion of morbidity administration and prevention of disabilities along \\
- $\quad$ enhance and put in force low-priced programs in morbidity \\
- $\quad \begin{array}{l}\text { interact individuals affected and their household participants in programs; and develop } \\
\text { referral mechanism to get entry to medical, social, and other entitlements; }\end{array}$
\end{tabular}

Source: World Health Organization (MMDP)

\section{Strengthening the MMDP Program}

Strong excessive degree dedication inside the Ministry of Health for LF morbidity alleviation and incapacity administration was imperative for sustaining and strengthening the MMDP program. Integrating filariasis administration with administration of different persistent illnesses such as diabetes, leprosy, or non-filarial lymphoedema (establishing lymphoedema administration facilities alternatively than filariasis clinics) was once encouraged as it would be cost-effective. Such a method would maximize the use of constrained sources as correctly as overcoming the social stigma of being labeled as a 'filariasis' by using the cause of attending Filariasis clinics. Publicity campaigns to elevate the attention of cure facilities would be an easy way to enhance their utilization. This ought to be executed with the aid of showing posters and banners at neighborhood centers, hospitals, and different fitness care facilities. The establishment of referral structures thru the essential fitness care carriers (medical officers, frequent practitioners, and area staff) would also enhance the utilization of clinics. Primary fitness care companies such as established practitioners, scientific officers at sanatorium outpatients-departments, and even consultants must be updated on modern-day lymphoedema administration techniques to make sure provision of excellent care.

\section{Conclusion}

Morbidity manipulation efforts inside the Global Programme to Eliminate Lymphatic Filariasis (GPELF) have focused on primary lymphoedema administration (hygiene, skincare, and easy bodily measures) to minimize the incidence of Acute Dermato Lymphangio Adenitis (ADLA) and forestall the development of lymphoedema and surgical restore of hydrocele. Since the Global Programme to Eliminate Lymphatic Filariasis (GPELF) was launched in 1998, a tremendous lookup has documented the effectiveness of simple lymphoedema administration \& improved scientific base for this intervention. Less work has been accomplished to report charges \& benefits of hydrocele surgical treatment in filariasis endemic areas. Other lookup is wished to aid efforts to 'scaleup morbidity manipulate and incapacity alleviation programs at countrywide stage $\&$ to report extent to which anti-filarial drug cure influences direction of filariasis associated disorder (David G Addis, 2007).

\section{References}

Addiss, David G., and Molly A. Brady. "Morbidity Management in the Global Programme to Eliminate Lymphatic Filariasis: A Review of the Scientific Literature." Filaria Journal, vol. 6, 2007.

Agrawal, VK., and VK. Sashindran. "Lymphatic Filariasis in India: Problems, Challenges, and New Initiatives." Medical Journal Armed Forces India, vol. 62, no. 4, 2006.

Cano, Jorge. et al. "The Global Distribution and Transmission Limits of Lymphatic Filariasis: Past and Present." Parasites \& Vectors, vol. 7, 2014.

Capuano, GP, and C Capuano. "Surgical Management of Morbidity due to Lymphatic Filariasis: The Usefulness of a Standardized International Clinical Classification of Hydroceles." Tropical Biomedicine, vol. 29, 2012, pp. 24-38.

Chandrasena, TGA Nilmini et al. "Lymphoedema Management Knowledge and Practices among Patients attending Filariasis Morbidity 
Control Clinics in Gampaha District, Sri Lanka." Filaria Journal, vol. 3, 2004.

Chu, Brian K., et al. "The Economic Benefits Resulting from the First 8 Years of the Global Programme to Eliminate Lymphatic Filariasis (2000-2007)." PLoS Neglected Tropical Diseases, vol. 4, 2010.

Dean, M. "Launching a Lymphatic Filariasis Campaign in the Pacific Islands." Lancet, vol. 356, 2000.

Deribe, Kebede. "Neglected Tropical Disease Targets must Include Morbidity." The Lancet Global Health, vol. 3, 2015.

Dreyer, G., et al. Treatment and Prevention of Problems Associated with Lymphatic Filariasis. WHO, 2001.

"Global Program to Eliminate Lymphatic Filariasis: Progress Report, 2016." Weekly Epidemiological Record, no. 40, 2017.

Gyapong, J.O., et al. "The Economic Burden of Lymphatic Filariasis in Northern Ghana." Annals of Tropical Medicine and Parasitology, vol. 90, 1996, pp. 39-48.

Ichimori, K. Lymphatic Filariasis: Managing Morbidity and Preventing Disability. WHO, 2013.

International Classification of Functioning, Disability, and Health. WHO, 2001.

Johnson, W. Surgical Approaches to the Urogenital Manifestations of Lymphatic Filariasis. WHO, 2019.

Krishnamoorthy, K. "Estimated Costs of Acute Adenolymphangitis to Patients with Chronic Manifestations of Bancroftian Filariasis in India." Indian Journal of Public Health, vol. 43, no. 2, 1999, pp. 58-63.

Kumari, A Krishna, et al. "Issues in Delivering Morbidity Management for Lymphatic Filariasis Elimination: A Study in Pondicherry, South India." Scientific World Journal, 2012.
Lymphatic Filariasis - Managing Morbidity and Preventing Disability; An Aide-Memoire for National Program Managers. WHO, 2013.

Lymphatic Filariasis: Monitoring and Epidemiological Assessment of Mass Drug Administration: A Manual for National Elimination Programmes. WHO, 2011.

"Lymphatic Filariasis: Progress of Disability Prevention Activities." Weekly Epidemiological Record, 2004, pp. 417-424.

Managing Morbidity and Preventing Disability in the Global Programme to Eliminate Lymphatic Filariasis. World Health Organization, 2011.

Mukhopadhyay, A. "Lymphatic Filariasis in Andhra Pradesh Paper Mill Colony, Rajahmundry, India after Nine Rounds of MDA program." Journal of Vector Borne Diseases, vol. 47, no. 1, 2010, pp. 55-57.

Preparing and Implementing a National Plan to Eliminate Elephantiasis in Countries where onchocerciasis is co-endemic. WHO, 2000.

Progress Report 2000-2009 and Strategic Plan 2010-2020 of the Global Programme to Eliminate Lymphatic Filariasis: Halfway towards Eliminating Lymphatic Filariasis. World Health Organization, 2010.

Ramaiah, K.D., et al. "Direct and Indirect Costs of the Acute Form of Lymphatic Filariasis to Households in Rural Areas of Tamil Nadu, South India." Tropical Medicine \& International Health, vol. 3, 1998.

Ramaiah, KD., et al. "The Economic Burden of Lymphatic Filariasis in India." Parasitology Today, vol. 16, no. 6, 2000, pp. 251-253.

Training Module on Community Home-based Prevention of Disability due to Lymphatic Filariasis. World Health Organization, 2003.

Wound and Lymphoedema Management. World Health Organization, 2010.

\section{Author Details}

Dr. A. Sangamithra, Professor, Department of Economics, Bharathiar University, Coimbatore, Tamil Nadu, India, EmailID: a.sangamithra@gmail.com.

P. Dhavamani, Ph.D. Research Scholar, Department of Economics, Bharathiar University, Coimbatore, Tamil Nadu, India, Email ID: dhavamaniperumal@gmail.com 